\title{
Increase of Oxidative Stress is Positively Associated with High-Sensitivity C-Reactive Protein in Women Using Combined Oral Contraceptives: An Observational Study
}

\section{Sabina Cauci ( $\nabla$ sabina.cauci@uniud.it )}

Department of Medicine, School of Medicine, University of Udine, Udine, 33100, Italy

\section{Maria Pia Francescato}

Universita degli Studi di Udine https://orcid.org/0000-0002-7892-863X

\section{Chiara Colannino}

Universita degli Studi di Udine

\section{Mattia Barbina}

Universita degli Studi di Udine

\section{Giuseppe Barbina}

Azienda Sanitaria Universitaria Integrata di Udine

\section{Serena Xodo}

Azienda Sanitaria Universitaria Integrata di Udine

\section{Research article}

Keywords: lipid peroxidation, free radicals, inflammationcontraceptive pillthromboembolismhormonal contraceptionestrogenprogestinthird generation pillalimentary habits

Posted Date: May 26th, 2020

DOl: https://doi.org/10.21203/rs.3.rs-27814/v1

License: () (1) This work is licensed under a Creative Commons Attribution 4.0 International License. Read Full License 


\section{Abstract \\ Background}

Information concerning oxidative stress and low-grade inflammation in oral contraception users is scarce. We investigated relationships of oxidative stress and high-sensitivity C-reactive protein (hsCRP) in women by oral combined contraceptive $(\mathrm{OC})$ use.

\section{Methods}

Caucasian Italian healthy non-obese women ( $\mathrm{n}=290$; 100 OC-users; 190 non-OC-users; mean age $23.2 \pm$ 4.7 years) were analyzed. Blood hydroperoxides, as oxidative stress biomarkers, were assessed by Free Oxygen Radical Test (FORT), and serum hsCRP was determined by routine methods.

\section{Results}

Oxidative stress levels were elevated ( $\geq 400$ FORT Units) in $77.0 \%$ and $15.8 \%$ of OC-users and non-OCusers, respectively (odds ratio $(O R)=209,95 \% \mathrm{Cl}=60.9-715.4, \mathrm{p}<0.001$ ); hsCRP levels $\geq 2.0 \mathrm{mg} / \mathrm{L}$ were found in $41.0 \%$ and $9.5 \%$ of $O C$-users and non-users, respectively $(\mathrm{OR}=6.6,95 \% \mathrm{Cl} 3.5-12.4, \mathrm{p}<0.001)$. Continuous hydroperoxides values in OC-users were 1.7-fold higher compared to non-users (median 472 versus 270 FORT Units, $p<0.001$ ); OC-users had 3.7-fold higher hsCRP values compared to non-OC-users (median 1.31 versus $0.35 \mathrm{mg} / \mathrm{L}, \mathrm{p}<0.001$ ). Hydroperoxides were strongly positively correlated to hsCRP in all women $\left(r_{s}=0.622, p<0.001\right)$, in OC-users $\left(r_{s}=0.442, p<0.001\right)$, and in non-OC-users $\left(r_{s}=0.426, p<0.001\right)$. Women with hydroperoxides $\geq 400$ FORT Units were 8 times as likely to have hsCRP $\geq 2 \mathrm{mg} / \mathrm{L}$. In non-OCusers only, hydroperoxides values were positively correlated with weight and body mass index, but negatively correlated with red meat, fish and chocolate consumption.

\section{Conclusions}

Our cross-sectional observational study is the first finding a strong positive correlation of serum hydroperoxides with hsCRP, a marker of inflammation. Further research is needed to elucidate the potential role of these two biomarkers in OC-use side-effects, like thromboembolism.

\section{Background}

The side effects of hormonal contraception are of increasing scientific interest because large studies and meta-analysis had assessed the association of oral combined contraceptive (OC) use with major complications, particularly cardiovascular diseases (CVDs) like arterial and venous thromboembolism (VTE), myocardial infarction, ischemic stroke, pulmonary embolism, peripheral arterial disease, and sudden cardiac death (1-11) but also some types of cancer including breast, uterine cervix, and liver and bile duct 
cancers (12-14). Moreover, a systematic review and meta-analysis (15) demonstrated a higher risk for preterm birth in women who had used OCs before pregnancy compared with a control group, whereas no association was found between OCs use and low birth weight risk, although a study (16) found lower birth weight among women who had used OCs for long duration. So far, however, biological pathways leading to increased risk of $\mathrm{OC}$ side effects are poorly explored and remain elusive in spite of the fact that many authors emphasise that this field require additional research.

Presently, few studies assessed oxidative stress (17-22) and low-grade inflammatory status (23-29) of OC-users pre-menopausal women, two conditions that are both implicated in several pathologies including CVDs and cancer. Rather surprisingly, however, no study ever examined the relationship between oxidative stress and low-grade inflammatory status in a sample of childbearing age women according to $\mathrm{OC}$ use. Importantly, both oxidative stress and low-grade inflammatory status can, at least in part, be modulated by lifestyles, including physical activity $(24,28,30-35)$.

The overproduction of reactive oxygen species (ROS) not balanced by the antioxidant defence, including enzymatic and non-enzymatic molecules, causes oxidative stress (36). Free radicals can attack various molecules (namely lipids, nucleic acids, proteins, etc.) becoming deleterious for the human body because of the formation of altered products (36). It is well established that oxidative stress has major roles in the pathogenesis of several diseases such as inflammatory, cardiovascular, muscular, and neurodegenerative diseases and cancer (36). However, ROS also have physiological positive roles indeed, free radicals contribute in signalling to regulate cell functions and inflammatory responses to microorganisms and xenobiotics (36).

Among fertile age women of the general population, only few studies evaluated oxidative stress according to $\mathrm{OC}$ use $(18-22,31,33)$ and attested by various biomarkers an increase of oxidative stress associated to hormonal contraception. Interestingly, recent data examining young female athletes showed a higher oxidative stress in OC-users compared to non-OC-users (17).

There is some evidence that $\mathrm{OC}$ use markedly raises the chronic low-grade inflammatory status as assessed by the increase of high-sensitivity C-reactive protein (hsCRP) (23-27). Elevation of hsCRP in young women implies several potential adverse effects including CVD risk $(37,38)$, endothelial damage, myocardial infarction, thromboembolic events (2). For assessment of CVD risk stratification, beyond the classical hsCRP values $<1,1$ to $3,>3 \mathrm{mg} / \mathrm{L}$ indicating lower, average or higher relative CVD risk (39), more detailed hsCRP thresholds have been proposed specifically for women as follows: $<0.5 \mathrm{mg} / \mathrm{L}$ (protective cutoff), $0.5-1.0 \mathrm{mg} / \mathrm{L}$ (no risk), $1.0<3.0 \mathrm{mg} / \mathrm{L}$ (intermediate risk), $3.0-<10.0 \mathrm{mg} / \mathrm{L}$ (high risk), and $\geq$ $10.0 \mathrm{mg} / \mathrm{L}$ (very high risk) (37). More recently the $2 \mathrm{mg} / \mathrm{L}$ hsCRP cutoff was used in primary CVD prevention to initiate statin therapy (39) or therapy to reduce inflammation and cardiovascular event rates by a monoclonal antibody targeting interleukin-1 $\beta$ (canakinumab) (40).

Progress in the understanding of mechanisms inducing oxidative stress and hsCRP in pre-menopausal women can furnish insights into the regulatory mechanisms underlying oxidative stress and chronic lowgrade inflammation induced damages and could promote further studies concerning the lifestyle and 
alimentary needs of young women OC-users, as these two serum biomarkers levels are potentially modifiable.

\section{Study objectives and aims}

The general aim of the study was to investigate the serum hydroperoxides (as indicator of oxidative stress) and hsCRP (as marker of chronic low-grade inflammation) levels in young women according to OC use, accounting for the effects of the alimentary habits and lifestyles. More specifically, we hypothesized that OC use might have some effect on continuous and stratified hydroperoxides and hsCRP levels.

\section{Methods}

\section{Design and setting of the study}

A cross-sectional observational study was conducted on healthy Italian adult women enrolled in the years from 2017 to 2019.

All participants attended once the Clinical Biochemistry laboratory of the Medical Department (University of Udine, Italy) early in the morning (8-10 am) and after $12 \mathrm{~h}$ fast; a finger capillary and a venous blood withdrawal $(23,24)$ was thus taken on seated subjects $(17,41)$. The day before, volunteers were asked to refrain from alcohol and supplement consumption as well as from physical exercise. Menstrual cycle phase was not accounted for; however, menstruation bleeding days were avoided (days 1 - 7 of menstrual cycle) because during the latter days oral contraception consists of drug discontinuation or placebo use. Clinical, demographic, and habit data were blinded to personnel executing the blood collection and samples measurements.

\section{Population}

Women (age range 18-46 years) were recruited consecutively; announcements at Udine University were used to enroll the volunteers.

All study participants filled questionnaires and volunteered for a venous and a finger capillary blood withdrawal. The inclusion criteria were: a) no acute (current/recent infection) or chronic disease such as diabetes mellitus, autoimmune diseases, thyroid or cardiovascular disease, or any tumor $(23,24)$; b) absence of pain from whatever cause (42); c) no assumption of anti-inflammatory drugs or antibiotics in the last 2 weeks $(23,24)$, d) no hormonal drugs other than monophasic combined contraceptive pills $(23$, 24), e) not lactating, pregnant, or postmenopausal (43); f) no present or past menstrual dysfunction (44); and h) no major sleeping disorders (17). Eligible women for inclusion in the OC-users group were those using a monophasic combined oral contraceptive for at least 3 months, whereas for inclusion in the nonOC-users control group, women had never used hormonal contraception or had discontinued since at least 3 months any hormonal treatment $(17,24)$. Three-hundred women were examined for eligibility; at the time of blood withdrawal, 10 women were excluded due to acute disease potentially affecting the inflammatory 
status. A total of 290 participants were thus included in the study ( $=100$ OC-users and $n=190$ non-OCusers).

Demographic factors, medical history and lifestyle habits (including smoking) were collected by a questionnaire. Moreover, a 2 weeks long diary allowed to collect alimentary habits in the form of daily number of servings as described in (17). Alimentary supplements consisted of a wide variety of commercial products containing variable amounts of single or mixed compounds, assumed by women occasionally, intermittently, or continually. Thus, alimentary supplements were not categorized into specific subgroups, and a categorical variable (yes or no) designed "supplement use" was employed for statistical analysis. Body mass index (BMI) was calculated as body mass $(\mathrm{kg})$ divided by the square of stature $(\mathrm{m})$.

\section{Ethical considerations}

Written informed consent was obtained from each participant before enrolment and no compensation or incentive was paid to the participants for this study. The study was approved by the Institutional Ethical Committee of the Department of Medicine (University of Udine), and was conducted according to the Declaration of Helsinki.

\section{Oxidative stress assessment}

Blood hydroperoxides (mainly consisting of lipid hydroperoxides; 17, 41) were determined in $20 \mu \mathrm{L}$ of capillary blood using the Free Oxygen Radical Test (FORT assay; Callegari, Parma, Italy), a 6 minute long colorimetric assay based on the ability of transition metals to catalyze the breakdown of hydroperoxides $(\mathrm{ROOH})$ into radicals, according to the Fenton reaction (41). The FORT assay has been validated to assess oxidative stress in human blood by various recent studies $(17,30,41,45)$. Results were expressed as FORT Units, whereby 1 FORT Unit corresponded to $0.26 \mathrm{mg} / \mathrm{L} \mathrm{H}_{2} \mathrm{O}_{2}$ (41). Variations of the intra- and inter-assay were both $<5.0 \%$. The range limits of measurable values were $\leq 160$ and $\geq 600$ FORT Units. Four non-OCusers had FORT values $\leq 160$ and were set at 160 FORT Units, whereby 9 OC-users had $\geq 600$ FORT Units and were set at 600 FORT Units for statistical calculations.

The threshold of 310 FORT Units was used as high cut-off level of hydroperoxides (17), and a value of 400 FORT Units was employed as very high threshold level of oxidative stress (46). The FORT assays has been validated for clinical use in women and has the advantage to be easily used in outpatient facilities $(30,45)$. Lewis, Newell (45) determined a value for individual biological variations of the FORT assay equal to $5.0 \%$.

\section{C-reactive protein measurement}

Just after collection, venous blood was processed for serum separation as already described (24).

Serum hsCRP was measured on Olympus AU5400 biochemistry analyzer (Olympus Diagnostic Systems Group, USA) using an ultra-sensitive immunoturbidimetric assay (Olympus System CRP latex). Detection limit of the assay was $\leq 0.1 \mathrm{mg} / \mathrm{L}$. Samples with values below the detection limit were set at $0.1 \mathrm{mg} / \mathrm{L}$ for statistical calculations. The intra- and inter-assay variations were $1.1 \%$, and $4.0 \%$, respectively. Stratification of hsCRP levels were performed as described $(23,37,39)$. 


\section{Statistical Analysis}

Normality of distribution of variables was assessed by the Kolmogorov-Smirnov test. Gaussian distributed data were shown as mean \pm standard deviation (SD). The FORT and hSCRP data were not normally distributed, thus, their values were shown as median and interquartile (IQR, $25^{\text {th }}$ to $75^{\text {th }}$ percentile) and nonparametric tests were used. Continuous variables were compared by the Mann-Whitney U-test. The comparison of proportions between groups was assessed by Pearson's $c^{2}$-test or Fisher's exact test, as appropriate; specifically, Fisher's test was used for variables "nulliparity" and "hsCRP $>10 \mathrm{mg} / \mathrm{L}$ ", for all other categorical variables Pearson's test was appropriate. Crude odds ratios (ORs) and $95 \%$ confidence intervals (Cls) were evaluated for categorical variables. Logistic regression was performed to evaluate the difference in oxidative stress between groups after adjustment for: age, BMI, smoking, supplement use, chocolate, fresh vegetable, fruits, red meat and fish servings per week. Bivariate relationships were evaluated by Spearman Rho test $\left(r_{s}\right)$. All tests were 2-sided. Statistical significance was set at $P$ values $<0.05$. At an alpha level of 0.01 , we had over $95 \%$ power to detect a difference in the proportion cases with hsCRP $\geq 2 \mathrm{mg} / \mathrm{L}$ between the OC-users and the non-OC-users groups and to find a correlation between hsCRP and FORT units with $r_{s}>0.4$. Statistical analysis was performed using the Statistical Package for Social Sciences (SPSS for Windows, SPSS Inc., Chicago, IL, USA).

\section{Results}

On average, the 290 study women were $23.2 \pm 4.71$ year-olds, had BMI $21.2 \pm 2.31 \mathrm{~kg} / \mathrm{m}^{2}, 97.9 \%$ were nulliparous, mostly enrolled at or employed by Udine University, $82.8 \%$ had University level education, $16.6 \%$ were smokers, and all had a middle-class socioeconomic status.

Main demographic and lifestyle characteristics and continuous values of oxidative stress and hsCRP of the 100 OC-users and the 190 non-OC-users are summarized in Table 1.

A normal weight range (BMI $18.0-25.0 \mathrm{~kg} / \mathrm{m}^{2}$ ) was found in $91.4 \%$ of women, 9 women were underweight $\left(3.1 \%, \mathrm{BMI}<18.0 \mathrm{~kg} / \mathrm{m}^{2}\right)$, and 16 were overweight $\left(5.5 \%, \mathrm{BMI}>25.0 \mathrm{~kg} / \mathrm{m}^{2}\right)$; none of the women, however, had a $\mathrm{BMI} \geq 30.0 \mathrm{~kg} / \mathrm{m}^{2}$. OC-users had slightly more frequently an University education (89.0\%) than nonOC-users (79.5\%), $\mathrm{p}=0.041$ (Table 1). However, most of the studied parameters were not significantly different between OC-users and non-OC-users including smoking habits, coffee and nutritional supplement use. In our sample, women smoke on average less than 1 cigarette per day. Only one smoker-woman smoked 26 cigarettes per day, none of the other smokers smoked more than 15 cigarettes per day.

Table 1 shows median (IQR) values of hydroperoxides that were 1.7-fold higher in OC-users compared to non-users (median 472 versus 270 FORT Units, $p<0.001$ ). Values of hsCRP were 3.7 -fold higher in OC-users compared to non-users (median 1.31 versus $0.35 \mathrm{mg} / \mathrm{L}, \mathrm{p}<0.001$ ).

Table 1. Comparison between the main characteristics of the two study groups. 


\begin{tabular}{|c|c|c|c|}
\hline Characteristic & $\begin{array}{l}\text { OC-users }^{a} \\
(n=100)\end{array}$ & $\begin{array}{l}\text { Non-OC-users }{ }^{a} \\
(n=190)\end{array}$ & $P$ value \\
\hline Age $^{\mathrm{a}}$ (years) & $22.7 \pm 3.50$ & $23.4 \pm 5.23$ & $0.887^{b}$ \\
\hline Weight $^{\mathrm{a}}(\mathrm{kg})$ & $60.1 \pm 7.59$ & $60.3 \pm 8.43$ & $0.921^{b}$ \\
\hline Height $^{\mathrm{a}}(\mathrm{m})$ & $1.68 \pm 5.94$ & $1.69 \pm 0.07$ & $0.752^{b}$ \\
\hline Body-mass index ${ }^{a}\left(\mathrm{~kg} / \mathrm{m}^{2}\right)$ & $21.2 \pm 2.24$ & $21.2 \pm 2.35$ & $0.993^{b}$ \\
\hline University education, n (\%) & $89(89.0)$ & $151(79.5)$ & $0.041^{c}$ \\
\hline Married, n (\%) & $5(5.0)$ & $19(10.0)$ & $0.142^{c}$ \\
\hline Nulliparity, n (\%) & $99(99.0)$ & $185(97.4)$ & $0.668^{d}$ \\
\hline Smokers, n (\%) & $21(21.0)$ & $27(14.2)$ & $0.139^{c}$ \\
\hline Cigarettes/day ${ }^{a}$ & $0.83 \pm 2.16$ & $0.75 \pm 2.68$ & $0.166^{\mathrm{b}}$ \\
\hline Coffee drinkers, n (\%) & $78(78.0)$ & $154(81.1)$ & $0.537^{c}$ \\
\hline Coffee cups ${ }^{e} /$ day & $1.2 \pm 1.02$ & $1.5 \pm 1.19$ & $0.055^{b}$ \\
\hline Nutritional supplement use, $\mathrm{n}(\%)$ & $23(23.0)$ & $29(15.3)$ & $0.103^{c}$ \\
\hline Oxidative stress (FORT units) & $472(403-532)$ & $270(229-308)$ & $<0.001^{b}$ \\
\hline $\mathrm{hsCRP}(\mathrm{mg} / \mathrm{L})$ & $1.31(0.79-3.34)$ & $0.35(0.17-0.72)$ & $<0.001^{b}$ \\
\hline
\end{tabular}

${ }^{\text {a }}$ Values are mean $\pm S D$ or median $\left(25^{\text {th }}-75^{\text {th }}\right.$ percentile $)$ as appropriate;

${ }^{\mathrm{b}} \mathrm{P}$ comparison of OC-users and non-OC-users by two-tailed Mann Whitney test;

${ }^{\mathrm{C}} \mathrm{P}$ comparison of OC-users and non-OC-users by two-tailed chi-square Pearson's test;

${ }^{\mathrm{d} P}$ comparison of OC-users and non-OC-users by two-tailed Fisher's exact test as appropriate;

e Italian espresso coffee cups.

Statistically significant differences are highlighted by bold characters. 
A hundred women were using OC from 3 to 144 months. OCs had different formulations but all were monophasic combined pills. Pills had variable progestin components: gestodene (43.0\%), drospirenone (24.0\%), desogestrel (12.0\%), levonorgestrel (10.0\%), cyproterone (4.0\%), dienogest (3.0\%), clormadinone (2.0\%), and nomegestrolo acetate (2.0\%). Overall, among the 100 OC-users second generation pill preparations (containing levonorgestrel) were used by $10.0 \%$, third generation pill preparations (having gestodene or desogestrel as progestin) by $55.0 \%$; and fourth generations pills (containing drospirenone, cyproterone, dienogest, clormadinone and nomegestrolo acetate) by $35.0 \%$ of women. Preparations containing progestogens with the highest risk of VTE according to recent evidence (5) including desogestrel, cyproterone, and drospirenone were used by $40.0 \%$ of OC-users.

Table 2 shows continuous values of hydroperoxides (FORT Units) and hsCRP (mg/L) in each generation pill users. Use of second generation pill was associated with lower values of hydroperoxides than third $(p=0.009)$ and fourth $(p=0.008)$ generation; conversely, third and fourth generation did not differ. Concentrations of hsCRP did not vary significantly among groups.

Table 2. Comparison of hydroperoxides and hsCRP values among the three different generation pills.

\begin{tabular}{|c|c|c|c|c|c|c|}
\hline Biomarker & $\begin{array}{l}2^{\circ} \\
\text { generation } \\
\text { OC-users }^{\mathrm{a}} \\
(\mathrm{n}=10)\end{array}$ & $\begin{array}{l}3^{\circ} \\
\text { generation } \\
\text { OC-users }^{\mathrm{a}} \\
(\mathrm{n}=55)\end{array}$ & $\begin{array}{l}4^{\circ} \\
\text { generation } \\
\text { OC-users }^{\mathrm{a}} \\
(\mathrm{n}=35)\end{array}$ & $\begin{array}{l}\mathrm{P}^{\mathrm{b}} \\
2^{\circ} \text { vs. } 3^{\circ} \\
\text { generation }\end{array}$ & $\begin{array}{l}\mathrm{P}^{\mathrm{b}} \\
2^{\circ} \text { vs. } 4^{\circ} \\
\text { generation }\end{array}$ & $\begin{array}{l}\mathrm{P}^{\mathrm{b}} \\
3^{\circ} \text { vs. } 4^{\circ} \\
\text { generation }\end{array}$ \\
\hline $\begin{array}{l}\text { Oxidative } \\
\text { stress } \\
\text { (FORT units) }\end{array}$ & $\begin{array}{l}366(332- \\
434)\end{array}$ & $\begin{array}{l}468(416- \\
530)\end{array}$ & $\begin{array}{l}491(434- \\
566)\end{array}$ & 0.009 & 0.008 & 0.236 \\
\hline $\begin{array}{l}\text { hsCRP } \\
\text { (mg/L) }\end{array}$ & $\begin{array}{l}1.06(0.83- \\
3.05)\end{array}$ & $\begin{array}{l}1.21(0.70- \\
3.39)\end{array}$ & $\begin{array}{l}1.67(0.86- \\
3.34)\end{array}$ & 0.592 & 0.445 & 0.898 \\
\hline
\end{tabular}

Second generation pill containing levonorgestrel; third generation pill containing gestodene and desogestrel; and fourth generation pills containing drospirenone, cyproterone, dienogest, clormadinone and nomegestrolo acetate.

a Values are median $\left(25^{\text {th }}-75^{\text {th }}\right.$ percentile);

${ }^{\mathrm{b}} \mathrm{P}$ comparison between generation pills by two-tailed Mann Whitney test.

Statistically significant differences are highlighted by bold characters.

In a further analysis, second generation pill users compared to all other pills showed lower hydroperoxides median 366 (IQR 332-434) versus 484 (IQR 421-542) FORT Units, $p=0.006$, but did not differ for hsCRP values $(p=0.509)$. Comparison of 55 users of third generation pills with other pill preparations did not show 
significant differences for hydroperoxides $(p=0.997)$ and hsCRP $(p=0.923)$. Fourth generation pill users were not different from the other pills in hydroperoxides $(p=0.083)$ and hsCRP $(p=0.753)$. However, by comparing the 40 users of $\mathrm{OC}$ at high risk of thromboembolism (i. e., those containing desogestrel, cyproterone, and drospirenone) with all the other remaining pills, oxidative stress was higher, median 492 (IQR 442-576) versus 444 (IQR 367-502) FORT Units, $p=0.003$, although hsCRP did not differ $(p=0.198)$.

\section{Stratified values of oxidative stress and hsCRP}

Table 3 shows the comparison of OC-users and non-OC-users according to categorized values of hydroperoxides and of hsCRP.

Table 3. Relative risk (OR) of OC-users versus non-OC-users for categorical values of oxidative stress and hsCRP. 


\begin{tabular}{|c|c|c|c|c|c|c|}
\hline \multirow[t]{3}{*}{ Measure } & $\begin{array}{l}\text { OC- } \\
\text { users }\end{array}$ & $\begin{array}{l}\text { Non-OC-Users } \\
(n=190)\end{array}$ & \multirow{3}{*}{$\begin{array}{l}\mathrm{OR}^{\mathrm{a}}(95 \% \\
\mathrm{Cl})\end{array}$} & \multirow{3}{*}{$P^{a}$} & \multirow[b]{2}{*}{$\begin{array}{l}\text { adjusted } \\
\mathrm{OR}^{\mathrm{b}}\end{array}$} & \multirow{3}{*}{$p^{b}$} \\
\hline & $(n=100)$ & \multirow[t]{2}{*}{$\mathrm{N}(\%)$} & & & & \\
\hline & $\mathrm{N}(\%)$ & & & & $(95 \% \mathrm{Cl})$ & \\
\hline FORT $\geq 310$ Units & $\begin{array}{l}92 \\
(92.0)\end{array}$ & 45 (23.7) & $\begin{array}{l}37.1(16.7- \\
82.1)\end{array}$ & $<0.001$ & $\begin{array}{l}100(30.1- \\
334)\end{array}$ & $<0.001$ \\
\hline FORT $\geq 400$ Units & $\begin{array}{l}77 \\
(77.0)\end{array}$ & $3(15.8)$ & $\begin{array}{l}209(60.9- \\
715)\end{array}$ & $<0.001$ & $\begin{array}{l}342(69.4- \\
1688)\end{array}$ & $<0.001$ \\
\hline $\mathrm{hsCRP}<0.5 \mathrm{mg} / \mathrm{L}$ & $\begin{array}{l}16 \\
(16.0)\end{array}$ & $118(62.1)$ & $\begin{array}{l}0.12(0.06- \\
0.21)\end{array}$ & $<0.001$ & $\begin{array}{l}0.07(0.03- \\
0.16)\end{array}$ & $<0.001$ \\
\hline $\begin{array}{l}\mathrm{hsCRP} \quad 0.5-<1.0 \\
\mathrm{mg} / \mathrm{L}\end{array}$ & $\begin{array}{l}22 \\
(22.0)\end{array}$ & $38(20.0)$ & $\begin{array}{l}1.13(0.62- \\
2.04)\end{array}$ & 0.689 & $\begin{array}{l}0.97(0.50- \\
1.91)\end{array}$ & 0.938 \\
\hline $\begin{array}{l}\mathrm{hsCRP} 1.0-<3.0 \\
\mathrm{mg} / \mathrm{L}\end{array}$ & $\begin{array}{l}29 \\
(29.0)\end{array}$ & 21 (11.1) & $\begin{array}{l}3.29(1.76- \\
6.15)\end{array}$ & $<0.001$ & $\begin{array}{l}4.30(1.99- \\
9.31)\end{array}$ & $<0.001$ \\
\hline $\begin{array}{l}\text { hsCRP } 3.0-<10.0 \\
\mathrm{mg} / \mathrm{L}\end{array}$ & $\begin{array}{l}28 \\
(28.0)\end{array}$ & $12(6.3)$ & $\begin{array}{l}5.77(2.78- \\
12.0)\end{array}$ & $<0.001$ & $\begin{array}{l}6.79(2.89- \\
16.0)\end{array}$ & $<0.001$ \\
\hline $\mathrm{hsCRP} \geq 1.0 \mathrm{mg} / \mathrm{L}$ & $\begin{array}{l}62 \\
(62.0)\end{array}$ & 34 (17.9) & $\begin{array}{l}7.49(4.33- \\
13.0)\end{array}$ & $<0.001$ & $\begin{array}{l}11.3(5.62- \\
22.7)\end{array}$ & $<0.001$ \\
\hline $\mathrm{hsCRP} \geq 2.0 \mathrm{mg} / \mathrm{L}$ & $\begin{array}{l}41 \\
(41.0)\end{array}$ & $18(9.5)$ & $\begin{array}{l}6.64(3.54- \\
12.4)\end{array}$ & $<0.001$ & $\begin{array}{l}11.1(4.90- \\
25.2)\end{array}$ & $<0.001$ \\
\hline $\mathrm{hsCRP} \geq 3.0 \mathrm{mg} / \mathrm{L}$ & $\begin{array}{l}33 \\
(33.0)\end{array}$ & $13(6.8)$ & $\begin{array}{l}6.71(3.33- \\
13.5)\end{array}$ & $<0.001$ & $\begin{array}{l}8.05(3.47 \\
-18.7)\end{array}$ & $<0.001$ \\
\hline $\mathrm{hsCRP} \geq 5.0 \mathrm{mg} / \mathrm{L}$ & $\begin{array}{l}14 \\
(14.0)\end{array}$ & $9(4.7)$ & $\begin{array}{l}3.27(1.36- \\
7.86)\end{array}$ & 0.006 & $\begin{array}{l}3.07(1.09- \\
8.66)\end{array}$ & 0.034 \\
\hline $\begin{array}{l}\mathrm{hsCRP} \geq 10.0 \\
\mathrm{mg} / \mathrm{L}\end{array}$ & $5(5.0)$ & $1(0.5)$ & $\begin{array}{l}9.95(1.15- \\
86.3)\end{array}$ & 0.020 & _c & -c \\
\hline
\end{tabular}

FORT, oxidative stress expressed in FORT units; hsCRP, high-sensitivity C-reactive protein; OR, odds ratio; $\mathrm{Cl}$, confidence interval.

$\mathrm{P}$ value calculated by two-tailed chi-square Pearson's or Fisher's exact test as appropriate.

aUnivariable OR;

${ }^{\mathrm{b}}$ Adjusted for age, body-mass index, smoking, supplement use, and chocolate, fresh vegetable, fruits, red meat and fish servings per week;

'Not measurable because of too low number of subjects in the compared groups.

Statistically significant differences are highlighted by bold characters. 
A marked difference was noted for hydroperoxides values $\geq 310$ FORT units, which were detected in $92.0 \%$ (92/100) of OC-users compared to $23.7 \%$ (45/190) of non-OC-users, crude OR=37.1, 95\% $\mathrm{Cl}=16.7-82.1$, $\mathrm{p}<0.001$, adjusted $\mathrm{OR}=100,95 \% \mathrm{Cl}=30.1-334, \mathrm{p}<0.001$. Very high levels of hydroperoxides $\geq 400 \mathrm{FORT}$ units were observed in $77.0 \%(77 / 100)$ of OC-users compared to $1.6 \%(3 / 190)$ of non-OC-users, crude OR=209, $95 \% \mathrm{Cl}=60.9-715.4, p<0.001$, adjusted $\mathrm{OR}=342,95 \% \mathrm{Cl}=69.4-1688, \mathrm{p}<0.001$.

The percentage of subjects with hsCRP concentrations $<0.5,0.5-<1.0,1.0-<3.0$, and $3.0-<10.0 \mathrm{mg} / \mathrm{L}$, was $16.0 \%, 22.0 \%, 29.0 \%$, and $28.0 \%$ in OC-users, and $62.1 \%, 20.0 \%, 11.1 \%$, and $6.3 \%$ in non-OC-users, respectively (Table 3). Very few women $(n=6)$ had hsCRP equal or over $10 \mathrm{mg} / \mathrm{L}, 5$ among the OC-users, and 1 among the non-OC-users. No woman had hsCRP $>20 \mathrm{mg} / \mathrm{L}$. The ORs for progressive cutoffs of hsCRP are shown in Table 3. Non-OC-users were much more likely to show protective hsCRP $<0.5 \mathrm{mg} / \mathrm{L}$ values compared to OC-users (OR 8.60; $95 \% \mathrm{Cl}=4.68-15.8, \mathrm{p}<0.001)$, however, they were similar to OC-users for not risky hsCRP levels $(0.5-<1.0 \mathrm{mg} / \mathrm{L})$. OC users compared with non-OC users had more frequently hsCRP risky levels, with crude OR ranging from 3.29 to 7.49 and adjusted OR ranging from 3.07 to 11.3 , as summarized in Table 3.

Relative risks of the 290 study women to have elevated hsCRP values among women with FORT ${ }^{3} 310$ or ${ }^{3}$ 400 Units are depicted in Table 4. Highly significant ORs were found for all the stratified levels considered with ODD ratio ranging from 8.3 to 10.2 for FORT ${ }^{3} 310$ Units and ORs ranging from 8.1 to 16.0 for FORT ${ }^{3} 400$ Units.

Table 4. Relative risk (OR) between two thresholds of elevated and low hydroperoxides for categorical hsCRP values. 


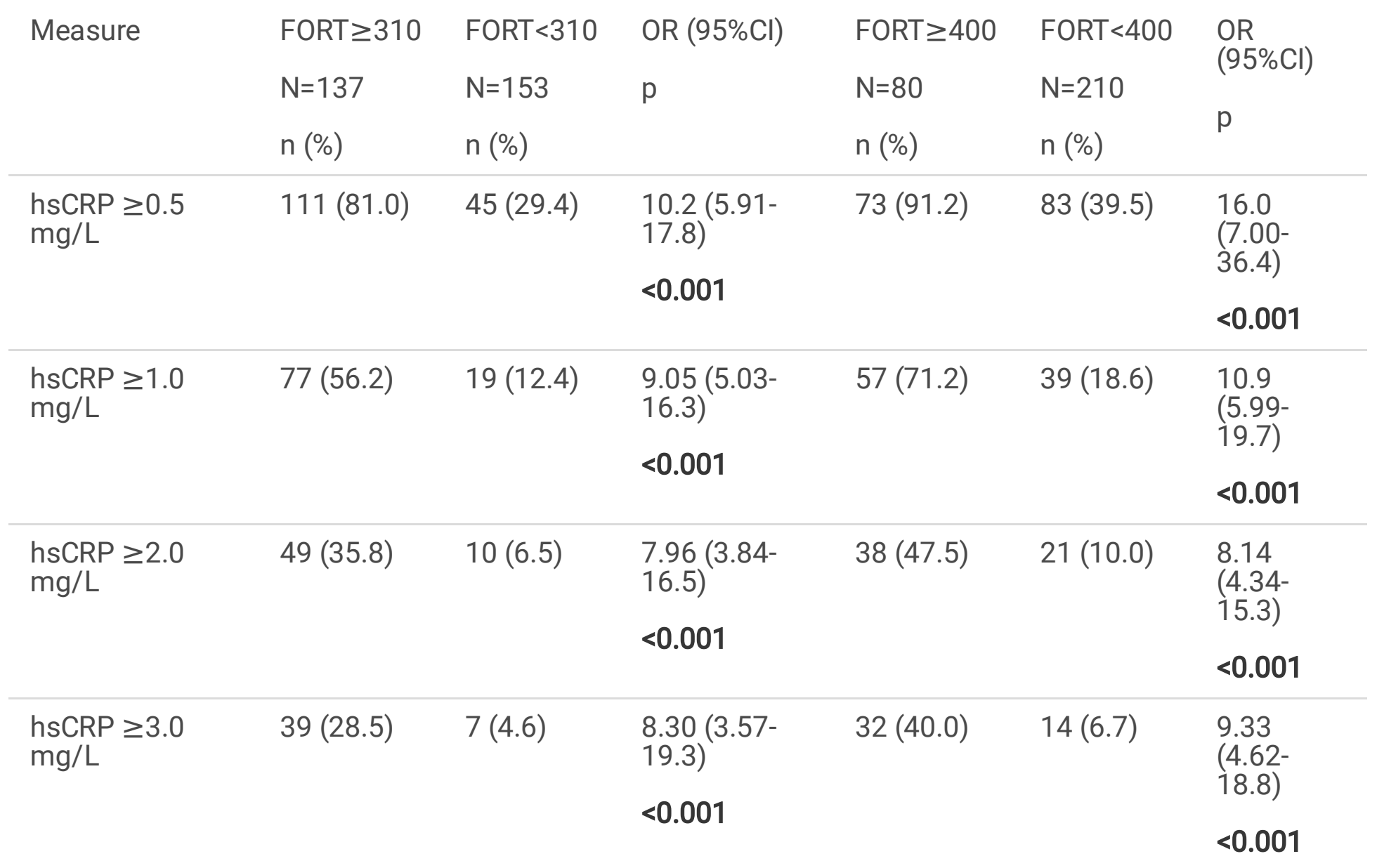

Two thresholds of elevated hydroperoxides levels ( $\geq 310$ or $\geq 400$ FORT Units) were compared with the corresponding low hydroperoxides levels ( $<310$ or $<400$ FORT Units, respectively) in the whole group of 290 women.

$\mathrm{OR}$, odds ratio; $\mathrm{Cl}$, confidence interval; $\mathrm{p}$ value by two-tailed chi-squared test.

Statistically significant differences are highlighted by bold characters.

Table 5 summarizes the correlations of hydroperoxides continuous values (in FORT units) with other biomarkers in all 290 study women, and separately in the 100 OC-users and 190 non-OC-users. FORT Units were highly positively correlated with hsCRP concentrations with $p<0.001$ in each of the 3 groups $\left(r_{s}=0.622\right.$, $0.442,0.426$, respectively). A positive association of FORT Units with body weight was found in non-OCusers only $(p=0.005)$. Oxidative stress showed significant positive associations with BMI in all women $(p=0.047)$ and non-OC-users $(p=0.001)$. Hydroperoxides showed significant inverse associations with red meat, fish and chocolate servings in all women ( $p=0.004,0.027,0.041$, respectively) and non-OC-users $(p=0.007,0.045,0.028$, respectively). Finally, we found an inverse correlation of hydroperoxides in all women with fruits $(p=0.035)$ and total meat servings $(p=0.029)$. Remarkably, with exception of hsCRP, none of the examined demographic, lifestyle/alimentary habits were associated with FORT Units in OC-users. 
Table 5. Correlations $\left(r_{s}\right)$ between continuous concentrations of oxidative stress and other lifestyle/alimentary biomarker continuous values. 
Characteristic

All women

OC-users

Non-OC-users

$(n=290)$

$(n=100)$

( $n=190)$

$r_{s}, p$ value $\quad r_{s}, p$ value $\quad r_{s}, p$ value

$\operatorname{hsCRP}(\mathrm{mg} / \mathrm{L})$

$0.622,<0.001$

$0.442,<0.001$

$0.426,<0.001$

Age, years

$0.041,0.489$

$0.047,0.644$

$0.080,0.274$

Weight, kg

$0.092,0.122$

$-0.011,0.910$

$0.207,0.005$

Height, $\mathrm{cm}$

$-0.013,0.822$

$-0.103,0.307$

$0.027,0.715$

BMI, $\mathrm{kg} / \mathrm{m}^{2}$

$\mathbf{0 . 1 1 8 , 0 . 0 4 7} \quad 0.061,0.547$

$0.252,0.001$

Cigarettes/day

$0.084,0.152$

$-0.002,0.985$

$0.029,0.696$

Coffee cups ${ }^{\mathrm{a}} /$ day

$-0.099,0.098$

$-0.118,0.251$

$0.029,0.701$

Tea cups/day

$0.079,0.188$

$0.078,0.447$

$-0.046,0.540$

Milk cups/week

$0.042,0.517^{\mathrm{b}}$

$0.135,0.204^{d}$

$0.032,0.700^{f}$

Yogurt, $125 \mathrm{~g}$ servings/week

$-0.035,0.593^{b} \quad-0.097,0.364^{d} \quad-0.053,0.521^{f}$

Cheese, $50 \mathrm{~g}$ servings/week

$-0.034,0.602^{b}$

$-0.006,0.955^{d}$

$0.040,0.630^{f}$

Rice, 80 g servings/week

$-0.031,0.634^{b}$

$0.130,0.222^{d}$

$-0.138,0.094^{f}$

Pasta, $100 \mathrm{~g}$ servings/week

$0.047,0.473^{b}$

$-0.122,0.252^{d}$

$0.103,0.210^{f}$

Fruits, $200 \mathrm{~g}$ servings/week

$-0.136,0.035^{b}$

$-0.167,0.115^{d}$

$-0.129,0.116^{f}$

Tomatoe/eggplant/pepper, plates/week

$0.009,0.891^{b}$

$-0.133,0.224^{d}$

$-0.008,0.930^{f}$

Fresh vegetables, plates/week

$-0.087,0.180^{b}$

$-0.066,0.537^{d}$

$-0.062,0.453^{f}$

Legumes, plates/week

$-0.023,0.726$

$-0.111,0.298^{d}$

$0.029,0.727^{f}$

Eggs, number/week

$-0.002,0.972^{b}$

$-0.051,0.641^{d}$

$0.051,0.542^{f}$

Red meat, $150 \mathrm{~g}$ servings/week

$-0.190,0.004^{b} \quad-0.031,0.777^{d}$

$-0.222,0.007^{f}$

Total meat (any type), $150 \mathrm{~g}$ servings/week

$-0.141,0.029^{b} \quad 0.022,0.839^{d}$

$-0.090,0.273^{f}$

Sausages, $50 \mathrm{~g}$ servings/week

$0.000,0.995^{\mathrm{b}}$

$0.043,0.686^{d}$

$0.054,0.511^{f}$

Fish, $200 \mathrm{~g}$ servings/week

$-0.143,0.027^{b} \quad-0.039,0.717^{d}$

$-0.164,0.045^{f}$

Sweet cakes, $50 \mathrm{~g}$ servings/week $-0.055,0.393^{b}$

$-0.025,0.813^{d}$

$0.072,0.382^{f}$

Chocolate, $50 \mathrm{~g}$ servings/week

$-0.132,0.041^{b} \quad-0.050,0.640^{d}$

$-0.180,0.028^{f}$ 


\begin{tabular}{llll} 
Wine, $125 \mathrm{~mL}$ glasses/week & $0.033,0.596^{\mathrm{c}}$ & $0.046,0.665^{\mathrm{e}}$ & $-0.005,0.945^{\mathrm{g}}$ \\
\hline Beer, $200 \mathrm{~mL}$ glasses/week & $0.080,0.199^{\mathrm{c}}$ & $0.096,0.360^{\mathrm{e}}$ & $0.057,0.466^{\mathrm{g}}$ \\
\hline Spirits, $40 \mathrm{~mL}$ glasses/week & $-0.008,0.900^{\mathrm{c}}$ & $-0.069,0.510^{\mathrm{e}}$ & $0.103,0.190^{\mathrm{g}}$
\end{tabular}

Two-sided Spearman correlations $\left(r_{s}\right)$ between continuous values of FORT units and other biomarker continuous values are summarized for all women sample $(n=290)$, and separately for the 100 OC-users and the 190 non-OC-users

a Italian espresso coffee cups; ${ }^{b}$ data available for 240 women; ${ }^{c}$ data available for 258 women; ${ }^{d}$ data available for 90 OC-user women; ${ }^{e}$ data available for 93 OC-user women; ${ }^{f}$ data available for 150 OC-user women; ${ }^{9}$ data available for 165 non-OC-user women.

Statistically significant differences are highlighted by bold characters.

\section{Discussion}

This is the first observational study assessing the relationships of oxidative stress (by hydroperoxides) and low-grade chronic inflammation (by hsCRP) levels by continuous and categorized serum values according to OC use in 290 Caucasian childbearing healthy women.

\section{Oxidative stress}

The median value of FORT Units was almost 2-fold higher in OC-users than in non-OC-users. We found a remarkable elevated frequency of high oxidative stress levels in healthy OC-users: by the cutoff value of $\geq 310$ FORT Units $92.0 \%$ (crude OR=37, adjusted OR=100 compared to non-OC-users), and by the cutoff value of $\geq 400$ FORT Units $77.0 \%$ (crude OR=209, adjusted OR=342). Evaluation of FORT Units relationships with other study parameters showed that oxidative stress apparently was not associated to OC-users lifestyles and alimentary habits. It appears that pro-oxidant effects of OCs likely overwhelmed antioxidant effects of lifestyle/alimentary good habits in OC-users. At variance, oxidative stress in non-OC-users was negatively associated with some alimentary habits, specifically chocolate, red meat and fish servings per week. Our findings are consistent with the known antioxidant properties of some foods (47-49). It is to mention that in our study fruits consumption had a negative correlation with oxidative stress in all the 290 women, however, in the distinct subgroups of 100 OC-users and 190 non-OC-users such negative correlation did not reach statistical significance, thus, fruits effects will require further research (48).

We did not found oxidative stress association with smoking and supplement consumption in the study women. The number of cigarettes smoked, however, was very low (on average $<1$ cigarette/day), moreover participants were asked to avoid supplements use in the day before blood testing. Interestingly, a study (30) performed in post-menopausal women showed that folate administration, in the form of 5methyltetrahydrofolate (5-MTHF), can reduce blood oxidative stress as assessed by FORT values reduction. Particular effects of supplements and/or drugs will require specific further research. 
Elevated BMI is known to increase systemic oxidative stress in the general population (50), and in active adults (32). Confirmatory with other studies, we found that BMI was positively correlated to the FORT levels in non-OC-user women only, but not in OC-users. A similar finding was seen previously in female athletes (17). Apparently, the strong OC induction of oxidative stress cancelled benefits deriving from reduced BMI.

Results of our current study performed on the general female population concur with a previous investigation evaluating oxidative stress in female athletes (17) founding that $42 \mathrm{OC}$-users had significantly higher hydroperoxides than 102 non-OC-users $(\mathrm{OR}=42,95 \% \mathrm{Cl}=12-149, \mathrm{p}<0.001)$. However, that study did not measured hsCRP (17).

A research conducted in 40-48 years old Belgian women found a significant increase of lipid peroxides in 209 OC-users compared to 119 non-users of contraception (22). A study comparing 32 OC-users with 30 non-OC-users found increased lipid peroxides $(+176 \%, p<0.001)$ and oxidized LDLs $(+145 \%, p<0.002)$ in the former group of women (20).

Interesting studies $(21,31)$ investigating the time-course of hydroperoxide elevation in women users of a low estrogen dose pill containing drospirenone demonstrated that oxidative stress increased significantly after only one week of $\mathrm{OC}$ use, remained constantly elevated during $\mathrm{OC}$ use, and returned to basal levels within one week of $\mathrm{OC}$ discontinuation, thus suggesting a causative role of $\mathrm{OC}$ use in increasing oxidative stress (31).

Mechanisms leading to elevation of hydroperoxides by OC are still not definitively characterized (31), however, some evidence point to oxidative hepatotoxicity of OC (12). P450 cytochromes (CYPs) catabolizing exogenous hormones can cause increased ROS production (51) and, in turn, hyper-production of free radicals could provoke depletion of antioxidant defenses such as depletion of reduced glutathione $(31,33)$. However, the role of estrogens and progestogens in OC induced oxidative stress is still debated $(20$, $31,52)$. An in vitro study showed that beta-estradiol treatment of cells resulted cytotoxic through oxidative stress provoking significant increase in lipid peroxidation (53).

By recent evidence tissue redox status is adequately reflected by redox blood biomarkers (54), thus, the increased oxidative stress measured in blood associated to OC use likely parallels increased free radicals also in several body organs (55).

\section{C-reactive protein}

In the present study, OC-use significantly increased all risky levels of hsCRP, while provoking a loss of the protective levels below $0.5 \mathrm{mg} / \mathrm{L}$. Specifically, OC-users were more likely to have hsCRP levels $\geq 1 \mathrm{mg} / \mathrm{L}$ (crude $O R=7.49$, adjusted $O R=11.3$ ); $\geq 2 \mathrm{mg} / \mathrm{L}$ (crude $O R=6.64$, adjusted $O R=11.1$ ); $\geq 3 \mathrm{mg} / \mathrm{L}$ (crude $O R=6.71$, adjusted $O R=8.05$ ) and $\geq 5 \mathrm{mg} / \mathrm{L}$ (crude $O R=3.27$, adjusted $O R=3.07$ ) than non-OC-users. Finally, OC-users were 9.95 times as likely to have hsCRP levels $\geq 10 \mathrm{mg} / \mathrm{L}$. These results are consistent with previous studies performed in 77 third generation pill OC-users (23) and 53 OC-users athletes (24). Our results are consistent also with a large Danish study finding low-grade inflammation (hsCRP 3-10 mg/L) in $29.9 \%$ of OC-users compared to $7.9 \%$ in non-OC users (26). 
The role of hsCRP attesting low-grade inflammation in women was highlighted by large studies: women who developed cardiovascular events had higher baseline hsCRP levels than control subjects, so that hsCRP was a strong independent risk factor for any vascular event $(\mathrm{RR}=4.8 ; 95 \% \mathrm{Cl}=2.3-10.1)$ and for myocardial infarction or stroke (RR=7.3; $95 \% \mathrm{Cl}=2.7-19.9)(56)$. Further studies confirmed the key role of chronic low-grade hsCRP in risk of future CVDs in women (39).

Recent evidence supports chronic inflammation (CRP values over $10 \mathrm{mg} / \mathrm{L}$ ) as a mechanism of ovarian carcinogenesis (57). Interestingly, one study (57) showed that ever users of OC had an increased risk for ovarian cancer ( $\mathrm{OR}=3.24,95 \% \mathrm{Cl}=1.62-6.47)$. Regarding breast cancer (14), a recent review stated that safety of long-term OC use for BRCA1/2 mutation carriers is uncertain, thus, non-hormonal contraceptive methods should be discussed with those women (13). Notably, combined estrogen plus progestogen contraceptives are considered human carcinogens and classified in Group 1 by the International Agency for Research on Cancer (14) for the liver and bile duct, breast and uterine cervix cancer.

Combined oral contraceptives may affect the mediators of low-grade chronic inflammation with potential additive risk in women with polycystic ovary syndrome (PCOS); however clinical implications of OC use by PCOS patients need further studies (29).

Inflammation (58) and oxidative stress (34) have been implicated in the etiology of depression and disturbed sleep (59); in turn, OC use has been associated with depression (60). More longitudinal research is needed to improve the understanding of mechanisms induced by inflammation in OC-users possibly affecting the psyconeurological pathways (61).

\section{Correlation between oxidative stress and hsCRP}

Overall, our data highlighted a strong positive correlation of hsCRP with oxidative stress $(p<0.001)$. Women with oxidative stress over 400 FORT units were eight time as likely to have hsCRP ${ }^{3} 2.0 \mathrm{mg} / \mathrm{L}$. So far, there has been a limited focus on this relationship specifically in women.

It is to highlight that causality cannot be inferred by our data, i.e., the design of our study does not allow to determine whether OC use directly increased ROS production (possibly via oxidative hepatotoxicity) that cause formation of hydroperoxides and then oxidative stress induces inflammation and/or whether OC use directly increase hsCRP that in turn provokes hydroperoxidation. It is to mention that the nuclear factors NF$\mathrm{kB} / \mathrm{kB}$ are key molecular switches both in oxidative stress and inflammation pathways (36), thus, molecular mechanisms could activate at the same time oxidative stress and inflammation.

Many potential adverse effects are linked to elevation of oxidative stress and inflammation including thromboembolic events, endothelial damage, CVDs, and cancer $(62,63)$. The biochemical pathways of oxidative stress and inflammation elevation in users of combined contraceptive pills have, however, to be still completely elucidated. 


\section{Impact of the composition of the contraceptive pill}

The progestin component of combined contraceptive pills may be important in determining side effects of OC use $(2,5,19)$. Recent studies demonstrated that hormonal contraception can modify the redox status in the vasculature of women using combined contraceptive pills containing low doses of ethinyl-estradiol and progestin agents such as drospirenone $(20,64)$ or norethisterone $(18)$.

New generations of OC pills are characterized by lower estrogen content and by newer progestins, like desogestrel, gestodene, cyproterone, and drospirenone with lower androgenicity than past generation pills (52). They have been introduced to reduce severe adverse effects of OC use, especially thromboembolism, and other cardiovascular diseases (11). However, these new OC preparations are still associated with the risk of pulmonary embolism, myocardial infarction, thrombotic stroke and VTE $(2,52)$. A meta-analysis of observational studies (6) found that all four generations of progestin were associated with an elevated risk of ischemic stroke, with a higher first-ever ischemic stroke risk associated with current OC use compared with non-current $\mathrm{OC}$ use (overall summary $\mathrm{OR}=2.47,95 \% \mathrm{Cl}=2.04-2.99$ ). The risk of ischemic stroke among current OC users decreased significantly with decreasing estrogen dose: OCs of $\geq 50 \mu \mathrm{g}$ ethinyl-estradiol (EE) had OR=3.28 (95\% Cl=2.49-4.32), 30-40 mg EE OR=1.75 (95\% Cl=1.61-1.89), $20 \mathrm{mg}$ EE OR=1.56 $(95 \% \mathrm{Cl}=1.36-1.79)$, whereas progestin only pills had not significant $\mathrm{OR}=0.99(95 \% \mathrm{Cl}=0.71-1.37)(6)$.

A Danish study (2) examined 1,626,158 nonpregnant women, 15-49 years-old, with no history of CVD or cancer. As compared with non-users, current use of OCs was associated with an absolute increased risk of thrombotic stroke and myocardial infarction, ranging from 0.9 to 1.7 for OC containing $20 \mathrm{mg} \mathrm{EE}$, and ranging from 1.3 to 2.3 for preparations with 30 to $40 \mathrm{mg} \mathrm{EE}$, with relatively small differences in risk according to progestin type (2).

The risk of VTE associated to OC use is of particular concern and has been recently investigated in a total of 10562 cases of thromboembolism (5). In respect to no exposure to OCs in the previous year, exposure to OC containing desogestrel had increased risk with OR of 4.28, cyproterone 4.27, drospirenone 4.12, gestodene 3.64, norethisterone 2.56, norgestimate 2.53, and levonorgestrel 2.38 (5). Similarly, another study (65) found that the relative risk of VTE for combined oral contraceptives with 30-35 $\mu$ g ethinyl-estradiol and gestodene, desogestrel, cyproterone acetate, or drospirenone were similar and about $50-80 \%$ higher than for combined oral contraceptives with levonorgestrel.

In our study we did not find statically significant differences in hsCRP values between users of second, third and fourth generation pills. However, second generation pill containing levonorgestrel had lower FORT values than third and fourth generation pills. Notably the group of OC containing desogestrel, cyproterone, and drospirenone had higher hydroperoxides values compared to all other progestins. Whether increased risk of thromboembolism in OC-users is mediated by the increased oxidative stress and/or chronic lowgrade inflammation needs further investigations are necessary to assess this relevant issue.

\section{Strengths and limitations}


Limits of our study include: recruitment of young adult Caucasian females, and thus, results cannot be generalized to older women and/or to women with different ethnic backgrounds; only women taking monophasic combined contraceptive pills were included in the study, excluding other types of contraceptive drugs; OCs were heterogeneous in type and amount of hormonal components although the majorities were OCs of third generation; detailed data about composition and dosing of potentially antioxidant supplements like vitamin $E, C$, and beta-carotene were not registered $(31,33)$. Finally, oxidative stress was evaluated by an assay measuring hydroperoxides (expression mainly of lipid peroxidation) $(31,41,63)$, that constitutes only one of the possible indirect markers to assess oxidative stress status (66); however, the FORT assays has been validated for clinical oxidative stress evaluation $(30,45)$.

Strengths of the present study include assessment of oxidative stress and hsCRP and several lifestyles and alimentary habits, the homogeneous ethnic group, the rather narrow age range of women, and strictly healthy subject inclusion.

Based on present data, increase of oxidative stress and hsCRP provoked by OC use poses the question of medical eligibility criteria for contraceptive use $(67,68)$, in particular for women affected by major diseases like high risk of CVDs, having had cancer or with major immune/inflammatory diseases like multiple sclerosis $(69)$, diabetes $(41,70)$ or HIV infection $(71,72)$.

\section{Conclusions}

This study adds to the existing evidence that $\mathrm{OC}$ use alters the oxidative homeostasis and modify lowgrade inflammatory status of young women. Our present findings showing a strong positive relationship between oxidative stress and basal chronic inflammation have several potential implications. We found elevated oxidative stress in the vast majority of OC-users (77\% with FORT ${ }^{3} 400$ Units), whereas hsCRP was considerably elevated in less than half the OC-users ( $41 \%$ with hsCRP $\left.{ }^{3} 2 \mathrm{mg} / \mathrm{L}\right)$. Although both parameters can potentially concur in OC side effects like the increased risk of CVDs, cancer and other diseases, oxidative stress seems even more crucial than inflammation, in particular since there is some lack of consensus about the role of hsCRP in CVD risk (39).

We also investigated lifestyle and alimentary habits of study women. OC-users appear resilient to antioxidant food and low BMI protective effects. However, in our opinion, future studies on food supplements having antioxidant and anti-inflammatory roles $(48,73,74)$ could be designed and especially targeted for OC-user women. Based on our data, concurrent use of pro-oxidant (74) and/or proinflammatory (75) drugs in addition to OC use should also be carefully taken into account, and will require future investigations. We think advisable that, at least in women with pathologic conditions and/or at high risk of developing a pathology, oxidative stress and hSCRP should be monitored over OC time use.

\section{Declarations}

Ethics approval and consent to participate 
Written informed consent was obtained from each participant before enrolment and no compensation or incentive was paid to the participants for this study. The study was approved by the Institutional Ethical Committee of the Department of Medicine (University of Udine), and was conducted according to the Declaration of Helsinki.

Consent for publication

Not applicable

Availability of data and materials

The datasets used and/or analysed during the current study are available from the corresponding author on reasonable request.

Competing interests

The authors declare that they have no competing interests

\section{Funding}

The study was perfomed with unconditional support from the University of Udine (Institutional grant to prof. S. Cauci; year 2017-2018 and 2019).

\section{Authors' contributions}

SC and MPF designed the study, equally contributed to the study by performing most of experiments, analyzed the data, and wrote the manuscript. CC, MB and GB contributed to the study by performing experiments. SX helped in the design of the study, enrolled the study subjects and reviewed the manuscript. SC supervised the project. All authors read and approved the final manuscript.

\section{Acknowledgements}

We thank Patrizia Nacci, Luca Bazzichetto, and Silvia Lolini for technical support and prof. Luigi Xodo for critical revision of the manuscript, Department of Medicine (University of Udine).

Authors' information (optional)

Not applicable

\section{Abbreviations}

BMI Body Mass Index

Cl Confidence interval

CVD Cardiovascular disease 
FORT Free Oxygen Radical Test

hsCRP high-sensitivity C-reactive protein

IQR interquartile range, from $25^{\text {th }}$ to $75^{\text {th }}$ percentile

OC oral combined contraceptive

OR odds ratio

PCOS polycystic ovary syndrome

ROS reactive oxygen species

$r_{s}$ Spearman's Rho correlation coefficient

VTE venous thromboembolism

\section{References}

1. Dragoman MV, Tepper NK, Fu R, Curtis KM, Chou R, Gaffield ME. A systematic review and metaanalysis of venous thrombosis risk among users of combined oral contraception. Int J Gynaecol Obstet. 2018;141(3):287-94.

2. Lidegaard O, Lokkegaard E, Jensen A, Skovlund CW, Keiding N. Thrombotic stroke and myocardial infarction with hormonal contraception. N Engl J Med. 2012;366(24):2257-66.

3. Roach RE, Helmerhorst FM, Lijfering WM, Stijnen T, Algra A, Dekkers OM. Combined oral contraceptives: the risk of myocardial infarction and ischemic stroke. Cochrane Database Syst Rev. 2015;8(8):CD011054.

4. Sacco S, Merki-Feld GS, KL AE, Bitzer J, Canonico M, Kurth T, et al. Hormonal contraceptives and risk of ischemic stroke in women with migraine: a consensus statement from the European Headache Federation (EHF) and the European Society of Contraception and Reproductive Health (ESC). J Headache Pain. 2017;18(1):108.

5. Vinogradova Y, Coupland C, Hippisley-Cox J. Use of combined oral contraceptives and risk of venous thromboembolism: nested case-control studies using the QResearch and CPRD databases. BMJ. 2015;350:h2135.

6. Xu Z, Li Y, Tang S, Huang X, Chen T. Current use of oral contraceptives and the risk of first-ever ischemic stroke: A meta-analysis of observational studies. Thromb Res. 2015;136(1):52-60.

7. Shufelt CL, Bairey Merz CN. Contraceptive hormone use and cardiovascular disease. J Am Coll Cardiol. 2009;53(3):221-31.

8. Zakharova MY, Meyer RM, Brandy KR, Datta YH, Joseph MS, Schreiner PJ, et al. Risk factors for heart attack, stroke, and venous thrombosis associated with hormonal contraceptive use. Clin Appl Thromb Hemost. 2011;17(4):323-31. 
9. Karabay CY, Kocabay G, Oduncu V, Kalayci A, Guler A, Karagöz A, et al. Drospirenone-containing oral contraceptives and risk of adverse outcomes after myocardial infarction. Catheter Cardiovasc Interv. 2013;82(3):387-93.

10. Gourbil M, Grandvuillemin A, Beyens MN, Massy N, Gras V, D'Amico A, et al. Thromboembolic events in women exposed to hormonal contraception or cyproterone acetate in 2012: a cross-sectional observational study in 30 French public hospitals. Drug Saf. 2014;37(4):269-82.

11. Lidegaard O. Hormonal contraception, thrombosis and age. Expert Opin Drug Saf. 2014;13(10):135360.

12. Kasper P. Cyproterone acetate: a genotoxic carcinogen? Pharmacol Toxicol. 2001;88(5):223-31.

13. Schrijver LH, Olsson H, Phillips KA, Terry MB, Goldgar DE, Kast K, et al. Oral Contraceptive Use and Breast Cancer Risk: Retrospective and Prospective Analyses From a BRCA1 and BRCA2 Mutation Carrier Cohort Study. JNCI Cancer Spectr. 2018;2(2):pky023.

14. International Agency for Research on Cancer. Classification by cancer cite. https://monographs.iarc.fr/wp-content/uploads/2019/07/Classifications_by_cancer_site.pdf, 2019. Accessed 01 april 2020.

15. Tang R, Ye X, Chen S, Ding X, Lin Z, Zhu J. Pregravid Oral Contraceptive Use and the Risk of Preterm Birth, Low Birth Weight, and Spontaneous Abortion: A Systematic Review and Meta-Analysis. J Womens Health (Larchmt). 2019.

16. Hatch EE, Hahn KA, Mikkelsen EM, Riis AH, Sorensen HT, Rothman KJ, et al. Pre-gravid oral contraceptive use in relation to birth weight: a prospective cohort study. Eur J Epidemiol. 2015;30(11):1199-208.

17. Cauci S, Buligan C, Marangone M, Francescato MP. Oxidative Stress in Female Athletes Using Combined Oral Contraceptives. Sports Med Open. 2016;2(1):40.

18. Chen JT, Kotani K. Oral contraceptive therapy increases oxidative stress in pre-menopausal women. Int J Prev Med. 2012;3(12):893-6.

19. Chen JT, Kotani K. Different Effects of Oral Contraceptive and Dydrogesterone Treatment on Oxidative Stress Levels in Premenopausal Women. J Clin Med Res. 2018;10(2):146-53.

20. De Groote D, Perrier d'Hauterive S, Pintiaux A, Balteau B, Gerday C, Claesen J, et al. Effects of oral contraception with ethinylestradiol and drospirenone on oxidative stress in women 18-35 years old. Contraception. 2009;80(2):187-93.

21. Finco A, Belcaro G, Cesarone MR. Assessment of the activity of an oral contraceptive on the levels of oxidative stress and changes in oxidative stress after co-treatment with two different types of physiological modulators with antioxidant action. Contraception. 2011;84(4):418-22.

22. Pincemail J, Vanbelle S, Gaspard U, Collette G, Haleng J, Cheramy-Bien JP, et al. Effect of different contraceptive methods on the oxidative stress status in women aged 4048 years from the ELAN study in the province of Liege, Belgium. Hum Reprod. 2007;22(8):2335-43.

23. Cauci S, Di Santolo M, Culhane JF, Stel G, Gonano F, Guaschino S. Effects of third-generation oral contraceptives on high-sensitivity C-reactive protein and homocysteine in young women. Obstet 
Gynecol. 2008;111(4):857-64.

24. Cauci S, Francescato MP, Curcio F. Combined Oral Contraceptives Increase High-Sensitivity C-Reactive Protein but Not Haptoglobin in Female Athletes. Sports Med. 2017;47(1):175-85.

25. Piltonen T, Puurunen J, Hedberg P, Ruokonen A, Mutt SJ, Herzig KH, et al. Oral, transdermal and vaginal combined contraceptives induce an increase in markers of chronic inflammation and impair insulin sensitivity in young healthy normal-weight women: a randomized study. Hum Reprod. 2012;27(10):3046-56.

26. Sorensen CJ, Pedersen OB, Petersen MS, Sorensen E, Kotze S, Thorner LW, et al. Combined oral contraception and obesity are strong predictors of low-grade inflammation in healthy individuals: results from the Danish Blood Donor Study (DBDS). PLoS One. 2014;9(2):e88196.

27. van Rooijen M, Hansson LO, Frostegard J, Silveira A, Hamsten A, Bremme K. Treatment with combined oral contraceptives induces a rise in serum C-reactive protein in the absence of a general inflammatory response. J Thromb Haemost. 2006;4(1):77-82.

28. Fedewa MV, Hathaway ED, Higgins S, Das BM, Forehand RL, Schmidt MD, et al. Interactive associations of physical activity, adiposity, and oral contraceptive use on C-reactive protein levels in young women. Women Health. 2018;58(2):129-44.

29. de Medeiros SF, de Medeiros MAS, Santos NS, Barbosa BB, Yamamoto MMW. Combined Oral Contraceptive Effects on Low-Grade Chronic Inflammatory Mediators in Women with Polycystic Ovary Syndrome: A Systematic Review and Meta-Analysis. Int J Inflam. 2018;2018:9591509.

30. Cagnacci A, Cannoletta M, Xholli A, Piacenti I, Palma F, Palmieri B. Folate administration decreases oxidative status and blood pressure in postmenopausal women. Eur J Nutr. 2015;54(3):429-35.

31. Finco A, Belcaro G, Cesarone MR. Evaluation of oxidative stress after treatment with low estrogen contraceptive either alone or associated with specific antioxidant therapy. Contraception. 2012;85(5):503-8.

32. Shanely RA, Nieman DC, Henson DA, Jin F, Knab AM, Sha W. Inflammation and oxidative stress are lower in physically fit and active adults. Scand J Med Sci Sports. 2013;23(2):215-23.

33. Zal F, Mostafavi-Pour Z, Amini F, Heidari A. Effect of vitamin E and C supplements on lipid peroxidation and GSH-dependent antioxidant enzyme status in the blood of women consuming oral contraceptives. Contraception. 2012;86(1):62-6.

34. Abshirini M, Siassi F, Koohdani F, Qorbani M, Mozaffari H, Aslani Z, et al. Dietary total antioxidant capacity is inversely associated with depression, anxiety and some oxidative stress biomarkers in postmenopausal women: a cross-sectional study. Ann Gen Psychiatry. 2019;18:3.

35. Ihalainen JK, Hackney AC, Taipale RS. Changes in inflammation markers after a 10-week high-intensity combined strength and endurance training block in women: The effect of hormonal contraceptive use. J Sci Med Sport. 2019;22(9):1044-8.

36. Sies H, Berndt C, Jones DP. Oxidative Stress. Annu Rev Biochem. 2017;86:715-48.

37. Cook NR, Buring JE, Ridker PM. The effect of including C-reactive protein in cardiovascular risk prediction models for women. Ann Intern Med. 2006;145(1):21-9. 
38. Kip KE, Marroquin OC, Shaw LJ, Arant CB, Wessel TR, Olson MB, et al. Global inflammation predicts cardiovascular risk in women: a report from the Women's Ischemia Syndrome Evaluation (WISE) study. Am Heart J. 2005;150(5):900-6.

39. Ridker PM. A Test in Context: High-Sensitivity C-Reactive Protein. J Am Coll Cardiol. 2016;67(6):712-23.

40. Ridker PM, MacFadyen JG, Everett BM, Libby P, Thuren T, Glynn RJ, et al. Relationship of C-reactive protein reduction to cardiovascular event reduction following treatment with canakinumab: a secondary analysis from the CANTOS randomised controlled trial. Lancet. 2018;391(10118):319-28.

41. Francescato MP, Stel G, Geat M, Cauci S. Oxidative stress in patients with type 1 diabetes mellitus: is it affected by a single bout of prolonged exercise? PLoS One. 2014;9(6):e99062.

42. Di Santolo M, Stel G, Banfi G, Gonano F, Cauci S. Anemia and iron status in young fertile nonprofessional female athletes. Eur J Appl Physiol. 2008;102(6):703-9.

43. Di Santolo M, Banfi G, Stel G, Cauci S. Association of recreational physical activity with homocysteine, folate and lipid markers in young women. Eur J Appl Physiol. 2009;105(1):111-8.

44. Casabellata G, Di Santolo M, Banfi G, Stel G, Gonano F, Cauci S. Evaluation of iron deficiency in young women in relation to oral contraceptive use. Contraception. 2007;76(3):200-7.

45. Lewis NA, Newell J, Burden R, Howatson G, Pedlar CR. Critical Difference and Biological Variation in Biomarkers of Oxidative Stress and Nutritional Status in Athletes. PLoS One. 2016;11(3):e0149927.

46. Kamhieh-Milz J, Salama A. Oxidative stress is predominant in female but not in male patients with autoimmune thrombocytopenia. Oxid Med Cell Longev. 2014;2014:720347.

47. Latif R. Health benefits of cocoa. Curr Opin Clin Nutr Metab Care. 2013;16(6):669-74.

48. Serafini M, Peluso I. Functional Foods for Health: The Interrelated Antioxidant and Anti-Inflammatory Role of Fruits, Vegetables, Herbs, Spices and Cocoa in Humans. Curr Pharm Des. 2016;22(44):6701-15.

49. Saita E, Kondo K, Momiyama Y. Anti-Inflammatory Diet for Atherosclerosis and Coronary Artery Disease: Antioxidant Foods. Clin Med Insights Cardiol. 2015;8(Suppl 3):61-5.

50. Keaney JF, Jr., Larson MG, Vasan RS, Wilson PW, Lipinska I, Corey D, et al. Obesity and systemic oxidative stress: clinical correlates of oxidative stress in the Framingham Study. Arterioscler Thromb Vasc Biol. 2003;23(3):434-9.

51. Modugno F, Knoll C, Kanbour-Shakir A, Romkes M. A potential role for the estrogen-metabolizing cytochrome P450 enzymes in human breast carcinogenesis. Breast Cancer Res Treat. 2003;82(3):1917.

52. Sitruk-Ware R, Nath A. Characteristics and metabolic effects of estrogen and progestins contained in oral contraceptive pills. Best Pract Res Clin Endocrinol Metab. 2013;27(1):13-24.

53. Yedjou C, Cameron J, Mbemi AT, Tchounwou P. b-estradiol induces cytotoxic effects to human Tlymphoma (Jurkat) cells through oxidative stress. J Miss Acad Sci. 2015;60:279-83.

54. Margaritelis NV, Veskoukis AS, Paschalis V, Vrabas IS, Dipla K, Zafeiridis A, et al. Blood reflects tissue oxidative stress: a systematic review. Biomarkers. 2015;20(2):97-108.

55. Savage KJ, Clarkson PM. Oral contraceptive use and exercise-induced muscle damage and recovery. Contraception. 2002;66(1):67-71. 
56. Ridker PM, Buring JE, Shih J, Matias M, Hennekens CH. Prospective study of C-reactive protein and the risk of future cardiovascular events among apparently healthy women. Circulation. 1998;98(8):731-3.

57. Peres LC, Mallen AR, Townsend MK, Poole EM, Trabert B, Allen NE, et al. High Levels of C-Reactive Protein Are Associated with an Increased Risk of Ovarian Cancer: Results from the Ovarian Cancer Cohort Consortium. Cancer Res. 2019;79(20):5442-51.

58. Mattina GF, Van Lieshout RJ, Steiner M. Inflammation, depression and cardiovascular disease in women: the role of the immune system across critical reproductive events. Ther Adv Cardiovasc Dis. 2019;13:1753944719851950.

59. Okun ML, Coussons-Read M, Hall M. Disturbed sleep is associated with increased C-reactive protein in young women. Brain Behav Immun. 2009;23(3):351-4.

60. Skovlund CW, Morch LS, Kessing LV, Lidegaard O. Association of Hormonal Contraception With Depression. JAMA Psychiatry. 2016;73(11):1154-62.

61. Lewis CA, Kimmig AS, Zsido RG, Jank A, Derntl B, Sacher J. Effects of Hormonal Contraceptives on Mood: A Focus on Emotion Recognition and Reactivity, Reward Processing, and Stress Response. Curr Psychiatry Rep. 2019;21(11):115.

62. Saghazadeh A, Hafizi S, Rezaei N. Inflammation in venous thromboembolism: Cause or consequence? Int Immunopharmacol. 2015;28(1):655-65.

63. Halliwell B. Free radicals and antioxidants: updating a personal view. Nutr Rev. 2012;70(5):257-65.

64. Massart A, Portier H, Rosado F, Toumi H, Filaire E. Lipid Peroxidation in Judoists Using Oral Contraceptives. International Journal of Sports Medicine. 2012;33(10):781-8.

65. de Bastos M, Stegeman BH, Rosendaal FR, Van Hylckama Vlieg A, Helmerhorst FM, Stijnen T, et al. Combined oral contraceptives: venous thrombosis. Cochrane Database of Systematic Reviews. 2014(3).

66. Finkler M, Lichtenberg D, Pinchuk I. The relationship between oxidative stress and exercise. J Basic Clin Physiol Pharmacol. 2014;25(1):1-11.

67. Centers for Disease Control and Prevention (CDC). U.S. Medical Eligibility Criteria for Contraceptive Use, (US MEC). https://www.cdc.gov/reproductivehealth/contraception/contraception_guidance.htm, 2016. Accessed 01 april 2020.

68. World Health Organization (WHO). Medical eligibility for contraceptive use. Fifth edition. Executive Summary. https://www.who.int/reproductivehealth/publications/family_planning/MEC-5/en/, 2015. Accessed 01 april 2020.

69. Houtchens MK, Zapata LB, Curtis KM, Whiteman MK. Contraception for women with multiple sclerosis: Guidance for healthcare providers. Mult Scler. 2017;23(6):757-64.

70. O'Brien SH, Koch T, Vesely SK, Schwarz EB. Hormonal Contraception and Risk of Thromboembolism in Women With Diabetes. Diabetes Care. 2017;40(2):233-8.

71. Centers for Disease Control and Prevention (CDC). Morbidity and Mortality Weekly Report (MMWR) https://www.cdc.gov/reproductivehealth/contraception/mmwr/mec/appendixc_tableC1.html\#mec_hiv, 2017. Accessed 01 april 2020. 
72. World Health Organization (WHO). Contraceptive eligibility for women at high risk of HIV. Guidance statement - Recommendations on contraceptive methods used by women at high risk of HIV. https://www.who.int/reproductivehealth/publications/contraceptive-eligibility-women-at-high-risk-ofHIV/en/, 2019. Accessed 01 april 2020.

73. Franco R, Martinez-Pinilla E. Chemical rules on the assessment of antioxidant potential in food and food additives aimed at reducing oxidative stress and neurodegeneration. Food Chem. 2017;235:31823.

74. Salimi A, Neshat MR, Naserzadeh P, Pourahmad J. Mitochondrial Permeability Transition Pore Sealing Agents and Antioxidants Protect Oxidative Stress and Mitochondrial Dysfunction Induced by Naproxen, Diclofenac and Celecoxib. Drug Res (Stuttg). 2019;69(11):598-605.

75. McComsey GA, Kitch D, Daar ES, Tierney C, Jahed NC, Melbourne K, et al. Inflammation markers after randomization to abacavir/lamivudine or tenofovir/emtricitabine with efavirenz or atazanavir/ritonavir. AIDS. 2012;26(11):1371-85. 